Jurnal Ekonomi Modernisasi

http://ejournal.unikama.ac.id/index.php/JEKO

JEM 13(1) 2017, 1-15

\title{
Pengaruh Service Quality, Marketing Mix dan Kepuasan Mahasiswa terhadap Customer Loyalty
}

\author{
Rokhmat Subagiyo', M. Aqim Adlan² \\ Fakultas Ekonomi dan Bisnis Islam IAIN Tulungagung
}

\begin{abstract}
The objective of the study was to analyze: (1) the influence of service quality factors directly and significantly to the satisfaction, (2) direct and significant influence of service marketing mix factor on student satisfaction, (3) the influence of service quality factor indirectly on the loyalty; (4) the influence of service marketing mix factor indirectly to loyalty, (5) the influence of student satisfaction factor directly to student loyalty. The research method used in this research was quantitative type explanatory research, sampling technique used was purposive sampling that was active student of Banking Syariah IAIN Banking Tulungagung as much as 320 students. Analysis technique using path analysis. The result of this research was service quality had a significant effect to student satisfaction, marketing mix had significant effect to student's satisfaction, service quality had no significant effect to student loyalty, marketing mix had significant influence to student loyalty and student's satisfaction had significant effect to student loyalty.
\end{abstract}

Keywords : Service Quality ; Marketing Mix, Student Satisfaction ; Student Loyalty

\section{Abstrak}

Tujuan penelitian ini adalah untuk mengetahui : (1) pengaruh faktor kualitas pelayanan secara langsung dan signifikan terhadap kepuasan, (2) pengaruh faktor bauran pemasaran jasa secara langsung dan signifikan terhadap kepuasan (3) pengaruh faktor kualitas pelayanan secara tidak langsung terhadap loyalitas; (4) pengaruh faktor bauran pemasaran jasa secara tidak langsung terhadap loyalitas (5) pengaruh faktor kepuasan mahasiswa secara langsung terhadap loyalitas mahasiswa. Metode penelitian yang digunakan dalam penelitian adalah kuantitatif research dan jenis penelitian adalah eksplanotry research, teknik sampling yang digunakan adalah purposive sampling yaitu mahasiswa aktif jurusan Perbankan Syariah sebanyak 320 orang. Teknik analisis menggunakan analisis jalur (path analysis). Hasil penelitian ini adalah kualitas pelayanan berpengaruh signifikan terhadap kepuasan mahasiswa, bauran pemasaran berpengaruh signifikan terhadap kepuasan mahasiswa, kualitas pelayanan tidak berpengaruh signifikan terhadap loyalitas mahasiswa, bauran pemasaran berpengaruh signifikan terhadap loyalitas mahasiswa dan kepuasan mahasiswa berpengaruh signifikan terhadap loyalitas mahasiswa.

Kata kunci: Kualitas Pelayanan ; Bauran Pemasaran ; Kepuasan Mahasiswa ; Loyalitas Mahasiswa

\author{
Permalink/DOI : http://dx.doi.org/10.21067/jem.v13i1.1567 \\ Cara mengutip $\quad$ : Subagiyo, R., \& Adlan, M. (2017). Pengaruh Service Quality, Marketing Mix dan \\ Kepuasan Mahasiswa terhadap Customer Loyalty. Jurnal Ekonomi Modernisasi, \\ 13(1), 1-15. doi:http://dx.doi.org/10.21067/jem.v13i1.1567
}

Sejarah Artikel : Artikel diterima : Januari 2017; direvisi Januari 2017; diterima Maret 2017

\footnotetext{
Alamat korespondensi :

Fakultas Ekonomi Dan Bisnis Islam, IAIN Tulungagung

Jl. Mayor Sujadi Timur No 46 Tulungagung Jawa Timur

E-mail:mat97.eca@gmail.com 


\section{Pendahuluan}

Saat ini kriteria produk jasa yang berkualitas harus diukur melalui konsep kepuasan pelanggan. Hal ini karena persaingan antara penyedia layanan jasa semakin meningkat sehingga penyedia jasa harus menekankan pada kualitas jasa melalui peningkatan kualitas pelayanan. Kualitas pelayanan menekankan pada kepuasan konsumen karena karakterstik produk jasa merupakan sesuatu yang tidak berwujud dan tidak bisa disimpan sehingga produk jasa yang dijual merupakan pelayanan yang ditawarkan kepada konsumen yang mempengaruhi kepuasan dan keinginan konsumen untuk melakukan pembelian ulang produk jasa yang ditawarkan. Oleh karena itu, merupakan hal penting bagi perusahaan untuk meningkatkan kualitas pelayanan yang mengukur kehandalan (reliability), jaminan dan kepastian (assurance), wujud (tangible), empati (Empathy) dan ketanggapan (responsiveness) (Parasuraman, Valarie, \& Leonard L, 1988).

Bauran pemasaran jasa (services marketing mix) merupakan faktor yang penting dan dibutuhkan sebagai strategi kegiatan pemasaran yang dijadikan acuan agar penerapan strategi pemasaran dan positioning yang ditetapkan dilakukan dengan baik. Terdapat perbedaan antara bauran pemasaran produk dengan bauran pemasaran jasa, karena karakteristik barang dan jasa yang berlainan. Menurut Tjiptono,(2005: 155), terdapat tujuh unsur bauran pemasaran jasa, meliputi: produk, harga promosi, tempat, orang, proses dan layanan konsumen.

Loyalitas pelanggan terhadap produk dapat ditentukan oleh salah satu dari produk, harga, promosi, tempat, orang, proses maupun layanan konsumen yang belum tentu disebabkan oleh kepuasan pelanggan.
Hal ini karena pelanggan yang loyalitas pelanggan tidak dapat diperoleh perusahaan terus menerus, jika pelanggan tersebut tidak memperoleh kepuasan maka cenderung bertindak negatif. Sebaliknya jika seseorang puas terhadap bauran pemasaran perusahaan maka pelanggan tersebut akan loyal terhadap perusahaan.

Jurusan Perbankan Syariah IAIN Tulungagung terus berupaya meningkatkan kualitas pelayanan berupa fasilitas fisik gedung berlantai enam, peralatan pendukung kegiatan belajar mengajar. Namun demikian,masih terdapat pegawai dan dosen di Fakultas Ekonomi dan Bisnis Islam IAIN Tulungagung masih belum dapat memberikan pelayanan yang maksimal kepada mahasiswanya, hal ini disebabkan bertambahnya jumlah mahasiswa yang tidak diikuti dengan peningkatan kualitas pelayanan melalui perbaikan kualitas sumber daya manusia yang ada.

Hal ini dapat berdampak kepada minat calon mahasiswa baru untuk masuk ke FEBI IAIN Tulungagung. Selain itu, terdapat pegawai yang sering meninggalkan pekerjaannya, sehingga pelaksanaan tugas administratif yang dilakukan menjadi terhambat,bahkan sering terdapat pekerjaan yang tertunda akibat pegawai yang mengerjakan pekerjaan tersebut tidak berada di ruang kerjanya.Oleh karena hal itu, merupakan hal penting bagi penyedia jasa perguruan tinggi untuk mengetahui sekaligus mengetahui dampaknya terhadap loyalitas.

\section{Tinjauan Pustaka}

\section{Service Quality}

Menurut Parasuraman et al., (1988) mendefinisikan service quality is a function of the differences between expectation and performance along the quality dimensions. Kualitas pelayanan jasa adalah perbedaan antara harapan dan 
kenyataan yang diterima oleh pelanggan. Menurut Bitner (1994) kualitas pelayanan merupakan keseluruhan kesan konsumen terhadap inferioritas/superioritas organisasi beserta jasa yang ditawarkan.Berdasarkan teori tersebut maka kualitas pelayanan adalah sebuah tingkat keunggulan dan merupakan output yang tidak berbentuk fisik yang mempunyai manfaat bagi pelanggan dan tingkat tinggi rendahnya berdasar pada harapan pelanggan. Oleh karena itu, kualitas pelayanan yang terbaik bersumber pada pendapat pelanggan dan bisa diperoleh secara konsisten dengan memperbaiki pelayanan dan memberikan perhatian khusus pada standar kinerja pelayanan baik standar pelayanan internal mapun standar pelayanan eksternal.

Definisi kualitas pelayanan menurut Lewis \& Blooms (1983: 99), Service quality is a measure of how well the service level delivered matches customer expectations." Definisi ini menekankan pada ukuran seberapa bagus tingkat layanan yang diberikan mampu sesuai dengan ekspektasi pelanggan. Oleh karena itu, kualitas pelayanan hanya bisa terwujud melalui pemenuhan kebutuhan dan keinginan pelanggan serta ketepatan penyampaian untuk mengimbangi harapan pelanggan.

\section{Dimensi Service Quality Perguruan Tinggi}

Penelitian yang dilakukan oleh Zeithaml, Parasuraman\& Berry (1988) yang melibatkan 800 pelanggan (yang terbagi dalam empat perusahaan) berusia lebih dari 25 tahun dapat disimpulkan bahwa terdapat lima dimensi SERVQUAL sebagai berikut: (1). dimensi Pertama, dari kualitas pelayanan menurut konsep SERVQUAL adalah berwujud (tangible) yaitu kemampuan suatu perusahaan dalam menunjukkan eksistensinya kepada pihak eksternal.; (2) dimensi Kedua, yakni kehandalan (reliability) adalah dimensi yang mengukur kemampuan perusahaan untuk memberikan pelayanan sesuai dengan yang dijanjikan secara akurat dan terpercaya; (3) dimensi Ketiga, ketanggapan (responsiveness) adalah suatu kebijakan untuk membantu dan memberikan pelayanan yang cepat dan tepat kepada pelanggan, dengan menyampaikan informasi yang jelas; (4) dimensi Keempat, Jaminan dan kepastian (assurance), yaitu pengetahuan kesopansantunan, dan kemampuan para pegawai perusahaan untuk menumbuhkan rasa percaya para pelanggan kepada perusahaan dan (5) dimensi Kelima, empati (emphaty) adalah memberikan perhatian yang tulus dan bersifat individual atau pribadi kepada para pelanggan dengan berupaya memahami keinginan konsumen.

Kualitas layanan jasa pendidikan tinggi, Garvin, (1987) mengusulkan delapan dimensi yang dapat menjelaskan baik kualitas produk dan layanannya, yaitu: (1) performance (kinerja), (2) features (fitur), (3) reliability (keandalan), (4) comformance (kesesuaian), (5) durability (daya tahan), (6) serviceability (kemampuan layanan), (7) aesthetics (estetika), (8) perceived quality (persepsi kualitas). Kualitas dalam pendidikan tinggi mungkin lebih sulit untuk didefinisikan daripada di sektor-sektor yang lain. McElwee and Redman (1993) menggunakan model dimensi kualitas pelayanan (SERVQUAL) yang dikembangkan oleh Parasuraman et al. 1988) sebagai dasar untuk model yang disesuaikan untuk pendidikan tinggi. Struktur rangka SERVQUAL, penekanan utamanya ditempatkan pada fungsional (interaktif) aspek kualitas. Hill, (1995) juga meneliti implikasi dari teori mutu pelayanan pendidikan tinggi.

Penggunaan jasa oleh pelanggan dipengaruhi oleh tingkat kualitas pelayanan, 
oleh karena itu kualitas pelayanan harus dikelola dengan baik sehingga pelanggan merasa puas. Kepuasan pelanggan dapat tercipta dengan adanya kualitas jasa pelayanan yang baik yaitu semakin tinggi tingkat kualitas pelayanan semakin besar kepuasan pelanggan yang dirasakan dan sebaliknya semakin rendah tingkat kualitas pelayanan maka semakin kecil kepuasan pelanggan yang dirasakan.

\section{Marketing Mix}

Kotler (2002),Marketing mix is the set of marketing tools that the firm uses to pursue its marketing objectives in the target market.McCarthy classified these tools into four broad groups that he called the four Ps of marketing: product, price, place, and promotion.Bauran pemasaran adalah sejumlah alat-alat pemasaran yang digunakan perusahaan untuk menyakinkan obyek pemasaran atau target pasar yang dituju. Bauran pemasaran (marketing mix) merupakan unsur-unsur pemasaran yang saling mempengaruhi satu sama lain sehingga bila salah satu tidak tepat pengorganisasiannya akan mempengaruhi strategi pemasaran secara keseluruhan. Penelitian ini menggunakan bauran pemasaran yang terdiri atas empat (4) variabel sesuai pendapat yang dikemukan oleh Kotler (1997), yaitu: (1) produk (product);

(2) harga (price); 3) promosi (promotion) dan (4) tempat (place on).

Perusahaan jasa harus berusaha menyusun kebijakan pemasaran yang terarah agar tercipta layanan yang efektif dan kepuasan pelanggan terwujud. Variabelvariabel pendukung dalam bauran pemasaran saling memberi dukungan yang selanjutnya perusahaan akan menggabungkan kombinasi tersebut supaya mendapatkan pasar sasaran yang tepat dan dapat mempengaruhi permintaan akan produknya. Lembaga pendidikan atau perguruan tinggi memiliki konsep terkait pedoman atau aturan tentang bauran pemasaran jasa yang terdiri atas kombinasi sepuluh (10) variabel inti dalam sistem pemasaran jasa pada pendidikan yang bisa dipakau untuk menjangkau konsumen sebagai pasar sasaran. Variabel-variabel pembentuk unsur pemasaran jasa tersebut dikombinasikan dan dikoordinasikan lembaga pendidikan agar melakukan tugas seefektif mungkin. Lembaga pendidikan tidak hanya memilih kombinasi yang terbaik saja, tetapi juga harus mengkoordinasikan berbagai macam elemen dari variabel bauran pemasaran jasa tersebut untuk melaksanakan kebijakan dan program-progamnya secara tepat.

\section{Kepuasan Mahasiswa}

Oliver dan Swan

mendefinisikan kepuasan pelanggan merupakan karakteristik pelanggan yang merasa surprise atas harapannya. Bery dan Parasuraman (1985) menjelaskan bahwa kepuasan pelanggan merupakan perbandingan antara layanan yang diharapkan (expectation) dan kinerja (performance). Menurut Boone dan Kurtz (1995), "customer satisfaction is the ability of goods or services to meet or exceed buyer need and expectations". Kepuasan pelanggan adalah apabila pelanggan membeli dan menggunakan suatu produk, dan mampu memenuhi bahkan melampaui kebutuhan dan harapannya.

Engel. et al (1995) menyatakan bahwa kepuasan pelanggan merupakan evaluasi purna beli yang memberikan hasil (outcome) sama atau melampui harapan pelanggan, sedangkan ketidakpuasan timbul apabila hasil yang diperoleh tidak memenuhi harapan pelanggan. Kotler (1997) mengungkapkan bahwa kepuasan pelanggan adalah perasan senang atau kecewa seseorang yang berasal dari perbandingan antara kesannya terhadap 
Rokhmat Subagiyo\& M. Aqim Adlan / Pengaruh Service Quality, Marketing Mix ....

kinerja (atau hasil) suatu produk dan harapan-harapannya. Adapun Supranto (2001) mendefinisikan kepuasan adalah tingkat perasaan seseorang setelah membandingkan kinerja/hasil yang dirasakannya dengan harapannya.

Berdasarkan pemahaman teori dapat disimpulkan bahwa kepuasan pelanggan merupakan evaluasi atas post consumption atas suatu barang atau jasa. Walaupun banyak definisi mengenai kepuasan pelanggan atau nasabah yang berbeda, namun hal penting adalah kepuasan pelanggan tidak dapat diukur dengan ukuran yang obyektif, kepuasan pelanggan harus dilihat secara abstrak dan merupakan fenomena yang bisa diukur dengan banyak indikator.

Pelanggan memutuskan membeli produk atau tidak dipengaruhi oleh banyak faktor diantaranya adalah pelayanan. Refleksi baik atau tidaknya pelayanan yang diberikan sebuah perusahaan terlihat oleh kepuasan atau ketidakpuasan pelanggan tersebut. Jika pelanggan puas maka semakin berpeluang untuk melakukan pembelian ulang di masa mendatang. Pelanggan yang merasa puas cenderung akan menyatakan hal-hal baik tentang produk dan perusahaan yang bersangkutan kepada orang lain.

\section{Customer Loyalty}

Founier dan Yao (1997) menyatakan bahwa loyalitas pelanggan merupakan suatu sikap yang menggambarkan perilaku aktual dari pelanggan yang tidak ditampakkan atau tidak disadari, tetapi analisis dan gambaran yang benar secara jelas diperlukan untuk mendasari struktur sikap dari pelanggan. Jacoby and Kyner (1973) menyatakan bahwa loyalitas pelanggan diekspresikan oleh enam kondisi yang diperlukan dan secara kolektif dengan mengintegrasikan dua pendekatan: kondisi ini mengekspresikan bahwa loyalitas merek adalah proses-proses (1) bias (misal, random), (2) respon perilaku (misal, pembelian), (3) waktu senggang, (4) dengan beberapa unit pengambilan keputusan, (5) dengan respek untuk satu atau lebih merek merek alternatif dari beberapa merek, dan (6) sebuah fungsi psikologis (pengambilan keputusan, evaluatif).

Uraian definisi tersebut dapat disimpulkan bahwa loyalitas (loyalty) merupakan serangkaian komitmen yang dipegang secara kuat untuk membeli ulang atau mendukung kembali terhadap produk atau jasa yang disukai pada masa yang akan datang walaupun ada pengaruh situasi dan kondisi dari lingkungan pemasaran memiliki potensi yang mengakibatkan pelanggan pindah pada produk atau jasa yang lain. Konsumen yang loyal dalam kondisi apapun dan dimana pun mempunyai komitmen yang teguh untuk tetap melakukan pembelian ulang dan pemakaian kembali barang dan jasa perusahaan tersebut.

Fatmah (2005) menjelaskan perkembangan loyalitas nasabah dibagi menjadi empat tahap yang dikenal dengan istilah "Model 4 Tahap Kekuatan Loyalitas" (The Four Stage Model of Loyalty Strenght) yang meliputi cognitive loyalty, affective loyalty, conative loyalty dan action loyalty. Model ini memberikan gambaran bahwa konsumen menjadi loyal lebih dahulu pada aspek kognitifnya, kemudian pada aspek afektif, dan diakhiri aspek konatif yang disertai motivasi dan komitmen. Berdasarkan uraian tersebut dapat dijelaskan bahwa loyalitas itu dapat menjadi terdiri dari empat fase yaitu (kognitif, afektif, konatif dan tindakan). Loyalitas mencakup dua hal yakni loyalitas sebagai perilaku dan loyalitas sebagai sikap.

Penelitian loyalitas pelanggan pada umumnya lebih menitikberatkan pada hal-hal yang erat kaitannya dengan produk atau loyalitas terhadap merek, namun demikian loyalitas pada perusahaan jasa sangat jarang 
diteliti (Blomer et. al, 1999). Loyalitas terhadap suatu jasa cenderung lebih tergantung pada hubungan antar individu, lainnya halnya dengan loyalitas pada barang yang berwujud. Bagi pemasaran jasa, pelanggan dan karyawan di lini depan berinteraksi untuk menciptakan jasa (Kotler, 2005). Jadi penyedia jasa harus bekerja untuk berinteraksi secara efektif dengan cara menempatkan ketrampilan karyawan jasa pada lini depan, dan pada produksi jasa serta proses pendukung karyawan ini..

Indikator dari loyalitas menurut Kotler dan Keller (2009) adalah (a). Repeat (kesetiaan terhadap pembelian produk) yaitu pembelian kembali atas hasil produk barang yang dibeli dari perusahaan tertentu. (b). Retention (Ketahanan terhadap pengaruh yang negatif mengenai perusahaan) adalah sikap konsumen yang hanya percaya pada produk tertentu dan kebal terhadap produk perusahaan lain sehingga tidak tertarik membeli produk perusahaan lain. (c). Referalls (mereferensikan secara total eksistensi perusahaan) adalah rekomendasi positif kepada orang lain tentang produk yang dipakai.

\section{Pengaruh Service Quality terhadap Kepuasan Mahasiswa}

Kualitas Pelayanan (Service Quality) memiliki peranan penting dalam menentukan kepuasan konsumen atau mahasiswa. Parasuraman dan Berry (1988), secara sederhana pengertian kualitas layanan dapat dinyatakan sebagai perbandingan antara layanan yang diharapkan konsumen dengan layanan yang diterimanya. Hasil penelitian yang sama juga dilakukan oleh Hendro Widodo (2015) yaitu dimensi kualitas memberikan pengaruh yang signifikan terhadap kepuasan mahasiswa Program Studi pendidikan guru Sekolah Dasar Universitas Ahmad Dahlan Yogyakarta. Penelitian yang dilaksanakan oleh I Ming Wang dan ChichJen Shieh (2006), terkait tentang pengaruh kualitas pelayanan terhadap kepuasan pengguna jasa perpustakaan Chang Jun Christian University, menyimpulkan bahwa kualitas pelayanan berpengaruh signifikan dan positif terhadap kepuasan pengguna jasa perpustakaan. Berdasarkan penjelasan diatas maka rumusan hipotesis adalah :

H1 : Kualitas pelayanan jasa berpengaruh positif terhadap kepuasan pelanggan.

\section{Pengaruh Service Quality terhadap Kepuasan Mahasiswa}

Dharmmesta dan Irawan (2007), mengemukakan, "Marketing mix atau bauran pemasaran adalah kombinasi dari empat variabel yaitu produk, struktur harga, kegiatan promosi, dan sistem distribusi. Keempat unsur bauran pemasaran tersebut saling berhubungan dan berpengaruh satu sama lain, sehingga harus diupayakan untuk menghasilkan suatu kebijakan pemasaran yang mengarah kepada layanan efektif dan kepuasan konsumen".

Jadi di dalam bauran pemasaran terdapat variabel-variabel yang saling mendukung satu dengan yang lainnya, yang selanjutnya oleh perusahaan digabungkan untuk memperoleh tanggapan-tanggapan yang diinginkan didalam pasar sasaran. Oleh karena itu, semakin baik perusahaan memahami kenginan konsumen maka konsumen akan semakin puas terhadap produk yang ditawarkan. Hal ini juga didukung penelitian Hatane Samuel (2006) menyimpulkan bahwa aplikasi bauran pemasaran berpengaruh secara signifikan terhadap kepuasan pelanggan.

Berdasarkan penjelasan diatas maka rumusan hipotesis adalah :

H2 : Bauran pemasaran jasa berpengaruh positif terhadap kepuasan pelanggan 
Rokhmat Subagiyo\& M. Aqim Adlan / Pengaruh Service Quality, Marketing Mix ....

\section{Pengaruh Kepuasan Mahasiswa terhadap Customer Loyalty}

Terdapat beberapa penelitian yang dilakukan tentang hubungan antara kualitas pelayanan dengan loyalitas pelanggan, diantaranya hasil penelitian Mokhtar and Maiyaki (2011) yang meneliti tentang pengguna jasa telepon seluler di Malaysia. Hasil penelitian yang dilakukan bahwa kualitas pelayanan memiliki hubungan positif yang signifikan dengan loyalitas pelanggan. Hasil penelitian ini serupa oleh Adimar (2016) tentang pengaruh kualitas pelayanan terhadap loyalitas mahasiswa Program Studi Manajemen Fakultas Ekonomi Universitas Taman Siswa Padang dengan hasil positif dan signifikan. Demikian pula yang dikatakan Reynold dan Arnold (2000) bahwa dengan adanya rasa puas, maka pelanggan akan melakukan pembelian ulang hanya pada satu pemasok saja, sehingga pelanggan akan menjadi setia pada pemasok tersebut. Bukti bahwa terdapat suatu hubungan yang positif antara kepuasan dan kesetiaan (loyalitas) yaitu bahwa semakin tinggi tingkat kepuasan akan membawa tingkat kesetiaan yang semakin tinggi pula. Berdasarkan penjelasan diatas maka rumusan hipotesis adalah :

H3 : Kepuasan mahasiswa berpengaruh positif terhadap loyalitas pelanggan

\section{Pengaruh Service Quality terhadap Customer Loyalty}

Kualitas pelayanan (Service Quality) yang terdiri atas tangibles, reliability, responsiveness, assurance, dan empatby yang positif berpengaruh langsung dengan indikator loyalitas pelanggan (Customer Loyalty) yaitu mengatakan hal yang positif (say positive things), memberikan rekomendasi kepada orang lain (recommend friend) dan melakukan pembelian terus-menerus (continue purchasing). Hasil penelitian Noventris Radja, Supramono, and Sulasmono (2013), menunjukkan bahwa kepuasan siswa berpengaruh positif dan signifikan terhadap loyalitas siswa kepada SMK Kristen Salatiga. Hal ini berarti semakin tinggi kualitas layanan yang diberikan dapat mempengaruhi kepuasan siswa, sehingga menimbulkan sikap loyal kepada SMK Kristen Salatiga. Berdasarkan penjelasan diatas maka rumusan hipotesis adalah :

H4 : Kualitas pelayanan berpengaruh positif terhadap loyalitas pelanggan

\section{Pengaruh Marketing Mix Terhadap Customer Loyalty}

Suprihanti (2011) telah melakukan penelitian tentang hubungan Bauran Pemasaran dengan loyalitas pelanggan KFC, dengan bahwa hasil bauran pemasaran mempunyai hubungan positif dan signifikan dengan loyalitas pelanggan. Hasil penelitian tersebut didukung oleh hasil penelitian Ayed (2012) yang menyatakan terdapat hubungan yang positif dan siginifikan antara bauran pemasaran dengan loyalitas turis di Yordania. Kemudian hasil penelitian dari Haryoso \& Suhartono (2012), sesuai dengan hasil penelitian Antik Suprihatini dan Ayed, yakni bauran pemasaran mempunyai hubungan yang positif dan signifikan. Berdasarkan penjelasan diatas maka rumusan hipotesis adalah :

H5: Bauran pemasaran berpengaruh positif terhadap loyalitas pelanggan

\section{Metode}

Pada penelitian ini digunakan pendekatan kuantitatif melalui metode survey. Teknik sampling adalah purposive sampling yaitu teknik penentuan sampel dengan mengambil sampel yang didasarkan pada pertimbangan tertentu. Jumlah sampel tidak bergantung dan berdasar besar kecilnya masing-masing populasi tiap level. Jumlah 
Jurnal Ekonomi Modernisasi, 13 (1) 2017, 1-15

populasi pada penelitian adalah 1.597 mahasiswa dengan menggunakan rumus Slovin diperoleh jumlah sample representatif sebesar 320 responden. Teknik analisis yang digunakan pada penelitian ini adalah path analysis.

\section{Hasil dan Pembahasan}

Berikut hasil analisis jalur pada penelitian ini

Tabel 1. Hasil Perhitungan Regresi Linear Berganda AntaraVariabel Kualitas Layanan Dan Bauran Pemasaran terhadap Kepuasan Pelanggan

\begin{tabular}{lcrrrr}
\hline \multicolumn{1}{c}{ Variabel } & \multicolumn{2}{c}{$\begin{array}{c}\text { Unstandardized } \\
\text { Coefficients }\end{array}$} & $\begin{array}{c}\text { Standardized } \\
\text { Coefficients }\end{array}$ & T hitung & Signifikansi \\
& B & Std. Error & Beta & & \\
Konstanta & $-0,796$ & 0,204 & & -3.902 & 0,000 \\
\hline Kualitas Pelayanan & 0,088 & 0,007 & 0,553 & 12.088 & 0,000 \\
\hline Bauran Pemasaran & 0,113 & 0,018 & 0,286 & 6.261 & 0,000 \\
\hline T tabel & 1,960 & & F tabel & 2,633 & \\
\hline $\mathrm{R}$ & 0,762 & & F hitung & 218,869 & \\
$\mathrm{R}^{2}$ & 0,580 & & Signifikansi F & 0,000 & \\
\hline
\end{tabular}

Sumber: Data Primer diolah

Tabel 2. Hasil Perhitungan Regresi Linear Berganda Antara Kualitas Pelayanan dan bauran Pemasaran Terhadap Loyalitas

\begin{tabular}{lcrrrr}
\hline \multirow{2}{*}{ Variabel } & \multicolumn{2}{c}{$\begin{array}{c}\text { Unstandardized } \\
\text { Coefficients }\end{array}$} & $\begin{array}{c}\text { Standardized } \\
\text { Coefficients }\end{array}$ & T hitung & Signifikansi \\
\cline { 2 - 4 } & \multicolumn{1}{c}{ B } & Std. Error & \multicolumn{1}{c}{ Beta } & & \\
\hline Konstanta & 2,695 & 0,226 & & 11.909 & 0,000 \\
\hline Kualitas Pelayanan & 0,003 & 0,008 & 0,028 & 0,417 & 0,677 \\
\hline Bauran Pemasaran & 0,088 & 0,020 & 0,294 & 4,388 & 0,000 \\
\hline T tabel & 1,980 & & F tabel & 2,03 & \\
\hline $\mathrm{R}$ & 0,312 & & F hitung & 17,099 & \\
\hline $\mathrm{R}^{2}$ & 0,097 & & Signifikansi F & 0,000 & \\
\hline
\end{tabular}

Sumber: Data Primer diolah 
Rokhmat Subagiyo\& M. Aqim Adlan / Pengaruh Service Quality, Marketing Mix ....

Tabel 3. Hasil Perhitungan Regresi Linear Berganda Antara Variabel Kepuasan Mahasiswa terhadap Loyalitas

\begin{tabular}{lcrrrr}
\hline \multirow{2}{*}{ Variabel } & \multicolumn{2}{c}{$\begin{array}{c}\text { Unstandardized } \\
\text { Coefficients }\end{array}$} & $\begin{array}{c}\text { Standardized } \\
\text { Coefficients }\end{array}$ & $\begin{array}{c}\text { T } \\
\text { hitung }\end{array}$ & $\begin{array}{r}\text { Signif } \\
\text { ikansi }\end{array}$ \\
\cline { 2 - 5 } & \multicolumn{1}{c}{ B } & Std. Error & Beta & & \\
\hline Konstanta & 3,287 & 0,119 & & 27,506 & 0,000 \\
\hline Kepuasan Mahasiswa & 0,249 & 0,040 & 0,329 & 6,213 & 0,000 \\
\hline T tabel & 1,980 & & F tabel & 3,87 & \\
\hline $\mathrm{R}$ & 0,329 & & F hitung & 38,605 & \\
\hline $\mathrm{R}^{2}$ & 0,108 & & Signifikansi t & 0,000 & \\
\hline
\end{tabular}

Sumber: Data Primer yang diolah

Tabel 4. Hubungan Langsung dan Tidak Langsung Antar Variabel

\begin{tabular}{lcll}
\hline \multicolumn{1}{c}{ Pengaruh } & Langsung & Tidak Langsung & Total \\
\hline $\begin{array}{l}\text { Kualitas Pelayanan } \longrightarrow \text { terhadap } \\
\text { Kepuasan Mahasiswa }\end{array}$ & 0,553 & & \\
\hline $\begin{array}{l}\text { Bauran Pemasaran } \longrightarrow \text { Kepuasan } \\
\text { Mahasiswa }\end{array}$ & 0,286 & & \\
\hline $\begin{array}{l}\text { Kepuasan Mahasiswa } \longrightarrow \text { Loyalitas } \\
\text { Mahasiswa }\end{array}$ & 0,028 & & \\
\hline $\begin{array}{l}\text { Kualitas Pelayanan } \longrightarrow \text { Kepuasan } \\
\text { Mahasiswa } \longrightarrow \text { Loyalitas Mahasiswa }\end{array}$ & & $0,553 \times 0,028=$ & $0,553+0,0155=$ \\
\hline $\begin{array}{l}\text { Bauran Pemasaran } \longrightarrow \text { Kepuasan } \\
\text { Mahasiswa } \longrightarrow \text { Loyalitas Mahasiswa }\end{array}$ & 0,0155 & 0,5685 \\
\hline
\end{tabular}

Sumber: Data Primer diolah

Pada tabel 1.dapat diketahui bahwa hasil perhitungan menunjukkan taraf signifikansi sebesar $0,000<0,05$ maka $\mathrm{H} 0$ ditolak dan H1 diterima yang berarti bahwaterdapat pengaruh langsung dan signifikan antara kualitas pelayanan terhadap kepuasan Mahasiswa Perbankan Syariah di FEBI IAIN Tulungagung. Hal ini bermakna bahwa peningkatan kualitas pelayanan diberikan dengan lebih baik maka Mahasiswa Perbankan Syariah di FEBI IAIN Tulungagung kepuasannya meningkat.

Hasil perhitungan pada tabel 1.juga menunjukkan taraf signifikansi sebesar 0,000 $<$ 0,05 maka H0 ditolak dan H1 diterima. Artinya, terdapat pengaruh secara langsung dan signifikan antara bauran pemasaran terhadap kepuasan Mahasiswa Perbankan
Syariah di FEBI IAIN Tulungagung. Hal ini diartikan bahwa apabila bauran pemasaran ditingkatkan lagi maka Mahasiswa Perbankan Syariah di FEBI IAIN Tulungagung akan bertambah tingkat kepuasannya.

Pada tabel 2 diketahui hasil perhitungan menunjukkan taraf signifikansi sebesar 0,677>0,05 maka H0 diterima dan H1 ditolak. Artinya, tidak ada pengaruh secara tidak langsung yang signifikan antara kualitas pelayanan terhadap loyalitas Mahasiswa Perbankan Syariah di FEBI IAIN Tulungagung. Hal ini berarti bahwa apabila kualitas pelayanan ditingkatkan lagi maka Mahasiswa Perbankan Syariah di FEBI IAIN Tulungagung tidak akan lebih loyal.

Hasil perhitungan ditunjukkan pada tabel 2. menunjukkan taraf signifikansi 
sebesar $0,000<0,05$ maka H0 ditolak dan H1 diterima. Artinya, terdapat pengaruh tidak langsung yang signifikan antara bauran pemasaran terhadap loyalitas Mahasiswa Perbankan Syariah di FEBI IAIN Tulungagung. Hal ini berarti bahwa apabila bauran pemasaran lebih diperhatikan maka Mahasiswa Perbankan Syariah di FEBI IAIN Tulungagungakan lebih loyal lagi.

Pada tabel 3 menunjukkan hasil perhitungan menunjukkan taraf signifikansi sebesar 0,000 < 0,05 maka H0 ditolak dan H1 diterima. Artinya, terdapat pengaruh langsung yang signifikan antara kepuasan mahasiswa terhadap loyalitas Mahasiswa
Perbankan Syariah di FEBI IAIN Tulungagung. Hal ini diartikan bahwa apabila kualitas pelayanan lebih diperhatikan maka Mahasiswa Perbankan Syariah di FEBI IAIN Tulungagung akan lebih loyal.Paparan mengenai pengaruh antar variable secara langsung, tidak langsung dan total disajikan dalam tabel 4, tentang hasil analisis jalur.

Oleh karena itu, secara keseluruhan dapat diketahui bahwa total pengaruh untuk meningkatkn loyalitas, lebih efektif melalui Kualitas Pelayanan terhadap Loyalitas dari pada Bauran Pemasaran terhadap Loyalitas.

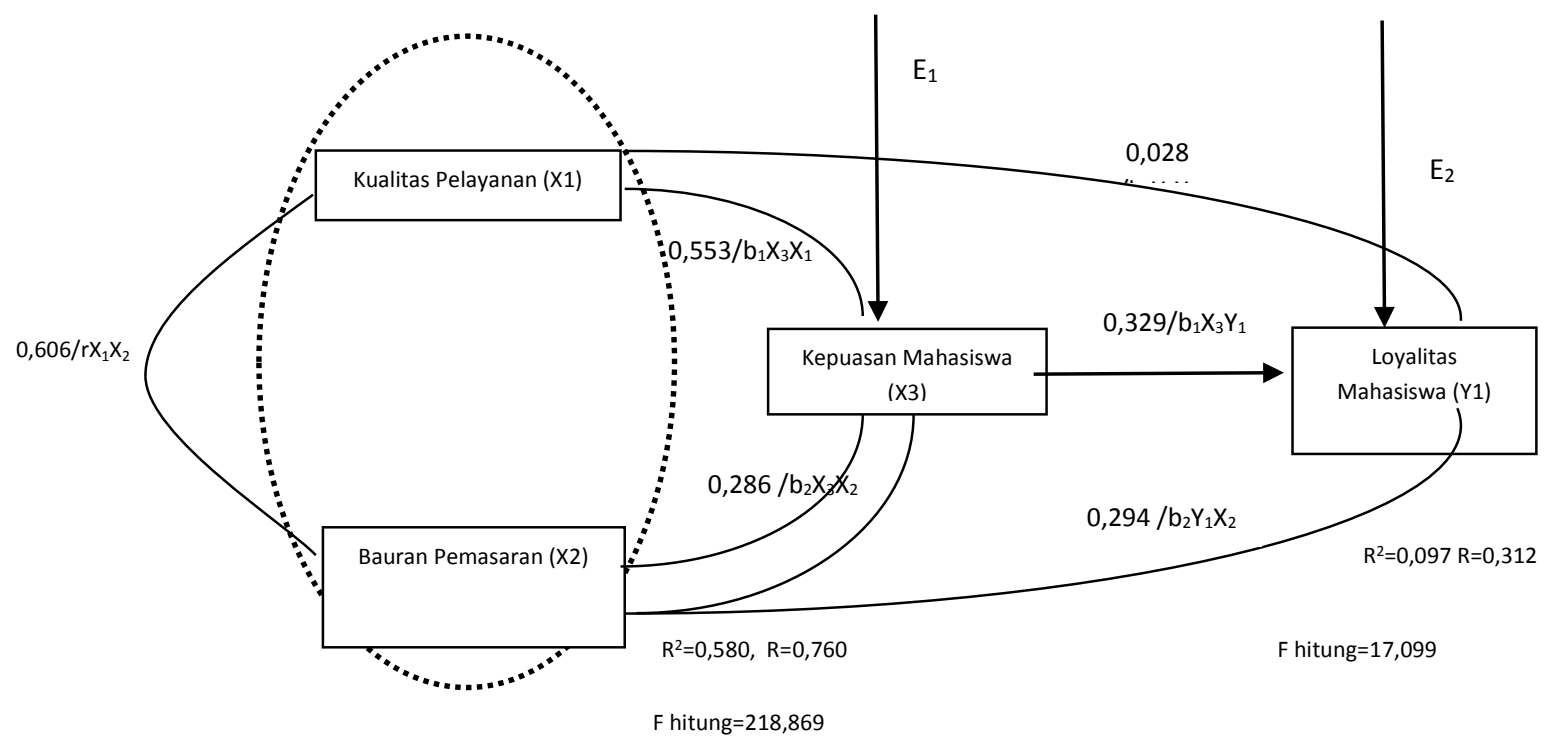

Gambar 1. Model Analisis Jalur Berdasarkan Hasil Perhitungan Regresi Linier

Pengaruh Kualitas Pelayanan Secara Langsung terhadap Kepuasan Mahasiswa

Kualitas pelayanan yang terbentuk dari lima (5) indikator yaitu bukti fisik, kehandalan, daya tanggap, jaminan dan kepastian serta empati yang telah menunjukkan telah dikelola dengan baik sehingga memberikan sumbangsih yang penting terhadap kepuasan mahasiswa, tetapiagar lebih meningkatkan kepuasaan mahasiswa dalam pelayanan yang diraih lebih baik perlu pengelolaan kualitas pelayanan yang lebih baik.

Hasil analisis data secara statistik membuktikan bahwa terdapat pengaruh signifikan secara langsung antara kualitas pelayanan terhadap kepuasan mahasiswa yang ditunjukkan dengan nilai standardized direct effect sebesar dapat diketahui bahwa 
Rokhmat Subagiyo\& M. Aqim Adlan / Pengaruh Service Quality, Marketing Mix ....

faktor kualitas pelayanan $\left(\mathrm{X}_{1}\right)$ memiliki nilai koefisien regresi 0,553 ; mempunyai nilai signifikansi $t$ sebesar 0,000 ; sehingga berpengaruh secara positif dan signifikan terhadap Kepuasan Mahasiswa.

Hasil ini pula didukung oleh teori mengenai kualitas pelayanan yang disampaikan oleh Parasuraman et.al (1985), yang mengatakan bahwa kualitas pelayanan jasa adalah perbedaan antara harapan dan kenyataan yang diterima oleh pelanggan.

Hasil deskriptif penelitian menunjukkan secara empiris rata-rata (mean) nilai kepuasan mahasiswa Perbankan Syariah sebesar 2,97 atau dibulatkan menjadi 3. Hal ini berarti mahasiswa menganggap biasabiasa saja (tidak terlalu baik atau buruk) atas lima (5) dimensi kualitas pelayanan jasa yang diberikan oleh pihak Fakultas Ekonomi dan Bisnis Islam (FEBI) IAIN Tulungagung, seperti bukti langsung (tangibles) ( $\left.\mathrm{X}_{1}\right)$, keandalan (reliability) $\left(\mathrm{X}_{2}\right)$, daya tanggap (responsiveness) $\left(\mathrm{X}_{3}\right)$, jaminan (assurance) $\left(\mathrm{X}_{4}\right)$, dan kepedulian (empatby) $\left(\mathrm{X}_{5}\right)$

\section{Pengaruh Bauran PemasaranSecara Langsung terhadap Kepuasan Mahasiswa}

Bauran pemasaranyang dibentuk oleh produk, harga, tempat dan promosi memiliki pengaruh yang positif dan signifikan terhadap kepuasan mahasiswa Perbankan Syariah di FEBI IAIN Tulungagung. Bauran pemasaran mempunyai nilai koefisien regresi 0,286; mempunyai nilai signifikansi t sebesar 0,000. Hal ini berarti apabila bauran pemasaran meningkat sebesar 1 (satu) satuan maka kepuasan mahasiswa akan meningkat sebesar 0,286 satu satuan pula.

Hasil penelitian ini konsisten dengan hasil penelitian Hatane (2006)bahwa aplikasi bauran pemasaran eceran berpengaruh positip terhadap kepuasan pelanggan. Hasil ini didukung juga oleh Afrida Shela Mevita dan Heru Suprihadi (2013) bahwa bauran pemasaran yang terdiri atas:produk, harga, saluran distribusi dan promosi berpengaruh terhadap kepuasan konsumen secara signifikan.Hal ini ini selaras dengan hasil jawaban responden yang terlihat pada tabel 3 seperti pada yang menunjukkan bahwa bauran pemasaran (marketing mix) yang terdiri dari produk, harga, saluran ditribusi dan promosi dengan anggapan yang cenderung positif yaitu dengan nilai rata-rata (mean) 3,48 atau dibulatkan menjadi 3,5.

\section{Pengaruh Kualitas Pelayanan Secara Tidak Langsung Terhadap Loyalitas Mahasiswa}

Kualitas pelayanan tidak memiliki pengaruh secara positif dan signifikan terhadap Loyalitas Mahasiswa. Hasil Penelitian ini sesuai dengan hasil penelitian yang dilakukan oleh Qomariah (2012), yang meneliti tentang Pengaruh Kualitas Layanan dan Citra Institusi Terhadap Kepuasan dan Loyalitas Pelanggan (Studi pada Universitas Muhammadiyah di Jawa Timur) dengan nilai signifikansi 0.9, yang berarti kualitas layanan tidak berpengaruh terhadap loyalitas mahasiswa. Hasil yang tidak didukungoleh penelitian yang dilakukan oleh Radja et al. (2013: 11) yang menyatakan bahwa ada pengaruh kualitas layanan SMK Kristen Salatiga terhadap loyalitas siswa melalui mediasi dengan variabel kepuasan siswa SMK Kristen Salatiga, dengan nilai signifkasi probabilitas 0,00 .

Secara empiris temuan dari hasil penelitian ini menunjukkan bahwa perusahaan dalam hal ini FEBI IAIN Tulungagung harus senantiasa meningkatkan kualitas pelayanannya agar kepuasan pelanggan atau mahasiswanya meningkat. Berdasar pada tabel 4 mahasiswa Perbankan Syariah merekomendasikan pada orang lain 
agar bersedia kuliah di FEBI IAIN Tulungagung. Nilai rata-rata 4,00, yang berarti mahasiswa Perbankan Syariah sudah loyal terhadap FEBI IAIN Tulungagung.

\section{Pengaruh Bauran Pemasaran Secara Tidak Langsung terhadap Loyalitas}

Bauran pemasaran berpengaruh signifikan terhadap loyalitas mahasiswa, Hasil penelitian ini konsisten dengan hasil penelitian Mevita and Suprihhadi (2013) yang mengatakan bahwa bauran pemasaran yang terdiri atas: produk, harga, saluran distribusi dan promosi berpengaruh terhadap kepuasan konsumen secara signifikan.Nilai signifikansi probalitas masing-masing sebesar 0,005, $0,004,0,006,0,000$ yang lebih kecil daripada 0,05. Hal ini sesuai dengan penelitiannya Iwan Ridwansyah dan Arif Maulana (2013) bauran pemasaran berpengaruh signifikan terhadap loyalitas mahasiswa universitas Widyamandala, dengan nilai signifikasi 0,00.

Secara faktual hasil ini sesuai dengan tanggapan responden terkait tempat (places) dengan indikator lokasi kampus FEBI IAIN Tulungagung dekat dengan jalan raya dengan rata-rata 4,103 (setuju); Kampus FEBI IAIN Tulungagung mudah dijangkau oleh kendaraan umum dengan nilai rata-rata 3,931 dan kampus FEBI IAIN Tulungagung mudah dicari dan diakses dengan nilai 3,975. Secara keseluruhan responden memberikan tanggapan untuk variabel bauran pemasaran sebesar 3,48 (bernilai positif).

\section{Pengaruh Kepuasan Mahasiswa Secara Tidak Langsung Terhadap Loyalitas Mahasiswa}

Kepuasan Mahasiswa pengaruh secara positif dan signifikan terhadap loyalitas mahasiswa. Hasil Penelitian ini tidak mendukung penelitian Nurul Qomariah (2012) yang menyatakan kepuasan mahasiswa tidak berpengaruh terhadap loyalitas nasabah, karena nilai signifikasi sebesar 0,9 namun selaras dengan hasil penelitian yang dilakukan oleh Kheng, Mahamad, Ramayah, and Mosahab (2010) dengan nilai koefisien 0,00. Jika dikaitkan dengan loyalitas nasabah, maka kualitas pelayanan berperan sebagai variabel pendahulu bagi terciptanya kepuasan nasabah (Dick dan Basu, 1994). Hasil penelitian ini sesuai dengan jawaban mahasiswa pada ketiga item pernyataan untuk variabel loyalitas mahasiswa rata-rata nilainya 4 (loyal), yang berarti loyalitas mahasiswa tinggi terhadap Fakultas Ekonomi dan Bisnis Islam (FEBI) IAIN Tulungagung.

\section{Simpulan}

Berdasarkan hasil penelitian maka simpulan pada peneltiian ini adalah :

Terdapat pengaruh langsung dan signifikan antara kualitas pelayanan terhadap Kepuasan Mahasiswa Perbankan Syariah FEBI IAIN Tulungagung, karena nilai signifikansi sebesar 0,000. Dengan besar pengaruh sebesar 0,553. Hasil ini mendukung hipotesis pertama. Hal ini berarti apabila kualitas pelayanan ini ditingkatkan, maka kepuasan mahasiswa Perbankan Syariah FEBI IAIN Tulungagung bertambah.

Bauran Pemasaran berpengaruh secara langsung dan signifikan terhadap Kepuasan Mahasiswa Perbankan Syariah FEBI IAIN Tulungagung, karena nilai signifikansi sebesar 0,000 . Besarnya pengaruh bauran pemasaran kepada kepuasan mahasiswa adalah 0,286. Hasil tersebut menerima hipotesis kedua, yang berarti apabila faktor-faktor pada bauran pemasaran meningkat, maka akan meningkatkan Kepuasan Mahasiswa Perbankan Syariah FEBI IAIN Tulungagung. Kualitas Pelayanan tidak memiliki pengaruh secara langsung dan signifikan terhadap Loyalitas Mahasiswa Perbankan 
Rokhmat Subagiyo\& M. Aqim Adlan / Pengaruh Service Quality, Marketing Mix ....

Syariah FEBI IAIN Tulungagung karena nilai signifikansi sebesar 0,667 , yang berarti sig. $(0,0067)>0,05$. Hasil ini tidak mendukung hipotesis ketiga, karena faktor-faktor kualitas pelayanan tidak menambah tingkat loyalitas Mahasiswa Perbankan Syariah FEBI IAIN Tulungagung secara langsung.

Terdapat pengaruh secara tidak langsung dan signifikan antara faktor-faktor Bauran Pemasaran terhadap Loyalitas Mahasiswa Perbankan Syariah FEBI IAIN Tulungagung, dengan nilai signifikansi 0,000 dengan besar pengaruh sebesar 0,294. Hal ini sesuai dengan hipotesis keempat, yang berarti semakin faktor-faktor bauran pemasaran ditingkatkan maka tingkat loyalitas Mahasiswa Perbankan Syariah FEBI IAIN Tulungagung akan meningkat pula

Kepuasan Mahasiswa berpengaruh langsung dan signifikan terhadap Loyalitas Mahasiswa Perbankan Syariah FEBI IAIN Tulungagung dengan nilai signifikasi sebesar 0,000 yang berarti mendukung hipotesis kelima yang diajukan dalam penelitian ini. Besarnya pengaruh kepuasan mahasiswa terhadap loyalitas mahasiswa sebesar 0,329. yang berarti semakin kepuasan mahasiswa ditingkatkan maka tingkat loyalitas Mahasiswa Perbankan Syariah FEBI IAIN Tulungagung akan meningkat pula.

\section{Daftar Pustaka}

Adimar, Febri. (2016). Pengaruh Kualitas Layanan Terhadap Loyalitas Mahasiswa Program Studi Manajemen Fakultas Ekonomi Universitas Tamansiswa Padang. Jurnal Fakultas Ekonomi Universitas

Tamansiswawww.journal.unitaspdg.ac.id/downlotfilemh.php?file...pdf , yang diakses pada 5 oktober 2016, pada 20.00 wib.

Ayed, A.M (2012) Assessing the Relationship between Marketing Mix and Loyalty through Tourists Satisfaction in Jordan
Curative Tourism, American Academic \& Scholarly Research Journal, 4(2)

Bitner, Mary Jo dan A.R. Hubber (1994). Encounter Satisfaction Versus Overall Satisfaction Versus Quality: The customer's Voice In Service Quality, New Direction In Theory and Practice, Sage Publication.

Blomer, Josoe. Ko De Ruyter dan Martin Netzels, (1999). Linking Perceved Service Quality and Service Quality: A Multi-dimensional

Perspective.European Journal of Marketing, 33(12)

Boone, Louis E., and David L. (1995). Kurtz. Contemporary Marketing Plus. (Eight Edition. International Edition). The Dryden Press.

Dharmmesta dan Irawan. (2007)Manajemen Pemasaran Modern. Edisi Kedua. Yogyakarta: BPFE.

Dick, A. S. dan K. Basu. (1994). Customer Loyalty: Toward an Integrated Conceptual Framework, Journal of Academy of Marketing Sciences, 22

Engel, James F, Roger D. Blackwell dan Paul W. Miniard. (1995). Consumer Behavior, $6^{\text {th }}$ Ed, Terjmh.Budijanto, "Perilaku Konsumen", Jakarta: Bina Rupa Aksara.

Fatmah,(2005).Pengaruh Persepsi Religuisitas, Kualitas Layanan dan Inovasi Produk Terhadap Kepercayaan dan Komitmen Serta Loyalitas Nasabah Bank Umum Syariah Di Jawa Timur.Disertasi Universitas Airlangga, Surabaya.

Fournier, S. \& Yao, (1997). J.L.Reviving brand loyalty: a conceptualization within the framework of consumerbrand relationships, Journal of Research in Marketing 14(5).

Haryoso\& Suhartono, (2012). Pengaruh Kualitas Pelayanan dan Bauran Pemasaran Terhadap Loyalitas 
Anggota dengan Kepuasan Anggota Sebagai Variabel Intervening (Studi Di Koperasi Kerabat SMP Negeri 1 Kebakkramat)",nn,e-journal.stieaub.ac.id/index.php/probank/.../57.d iakses pada 15 Desember 2012, pada 20.00 WIB.

Widodo, H. (2015). Analisis Kualitas Pelayanan Terhadap Kepuasan Mahasiswa Program Studi Pendidikan Guru Sekolah Dasar", JURNAL JPSD Jurnal Pendidikan Sekolah Dasar), 2015, UAD, http://journal.uad.ac.id/index.php/JP $\underline{\mathrm{SD} / \text { article/download/2524/1505, }}$

http://repository.usu.ac.id/bitstream/12345 6789/40121/4/Chapter\%20II.pdf.yan g diakses pada 6 Oktober 2016, pukul 11.30WIB.

Jacoby, J. \& Kyner, D.B. (1973). Brandloyalty vs.Repeat purchasing behavior.Journal of Marketing Research, 10, February

Kheng, L. L., Mahamad, O., Ramayah, T., \& Mosahab, R. (2010). The Impact of Service Quality on Customer Loyalty: A Study of Banks in Penang, Malaysia. International Journal of Marketing Studies, 2(2).

.Kotler, P. (1997). Marketing Management, Terjemh. Hendra Teguh dan Ronny A. Rusly, Manajemen Pemasaran, Jakarta: PT. Prenhalindo.

Kotler, P. (2000). Marketing, Penerjemah: Herujati Purwoko, Jilid 1, Cetakan Ketiga. Jakarta: Erlangga,

Kotler, P. (2002). Marketing Management. Millenium Edition. Boston: Pearson Custom Publishing,

Kotler, P.\& Gary, Armstrong. (2005) DasarDasar Pemasaran. Diterjemahkan oleh : Alexander Sindoro, Jilid 1. Edisi Kesembilan. Jakarta: PT. Indeks,

Kotler, P \& Keller. (2009). Manajemen Pemasaran. Jilid I. Edisi ke 13. Jakarta: Erlangga.
Lewis, R.C. \& Booms, B.H. (1983), "The marketing aspects of service quality" in Berry, L., Shostack, G. and Upah, G. (eds.), Emerging perspectives on services marketing, American Marketing Association Chicago, pp. 99-104.

McElwee, G., \& Redman, T. (1993). Upward Appraisal in Practice: An Illustrative Example Using the Qualed Model. Education + Training, 35(2). doi:10.1108/eum0000000000298

Mevita, A. S., \& Suprihhadi, H. (2013). Pengaruh Bauran Pemasaran Terhadap Kepuasan Konsumen. Jurnal Ilmu \& Riset Manajemen, 2(9).

Mital, Vikas, William T. Ross and Patrick M Baldasare. (1998) The AsymetricImpact of Negative and Positive Attribute Level Performance on OverallSatisfaction and Repurchase Intentions," Journal of Marketing62 (2)

Mokhtar, S. S. M., \& Maiyaki, A. A. (2011). The Relationship Between Service Quality and Satisfaction on Customer Loyalty in Malaysian Mobile Communication Industry. School of Doctoral Studies (European Union) Journal, 32-38.

Oliver, Richard L dan Jhon E Swan (1989). Consumer Perceptions of Interpersonal Equity and Satisfaction in Transaction: a Field Survey Approach, Journal Marketing, 1989.

Parasuraman, A., Zeithaml, V.A. and Berry, L.L. 2005. "A conceptual model of service quality and its implications for future research", Journal of Marketing , 49(3)

Parasuraman, A., Valerie Zeithaml, and L.Berry. (1988).Servqual: Multiple Item Scale for Measuring Consumer Perceptions of Service Quality, Journal of Retailing, 64 (15), 12-36

Qomariah, Nurul, (2012). Pengaruh Kualitas Layanan dan Citra Institusi Terhadap Kepuasan dan Loyalitas Pelanggan (Studi pada Universitas 
Rokhmat Subagiyo\& M. Aqim Adlan / Pengaruh Service Quality, Marketing Mix ....

Muhammadiyah di Jawa Timur), Vol.

10 no 1, Maret. Jurnal Aplikasi Manajemen.

Radja, N. R., Supramono, \& Sulasmono, B. S. (2013). Pengaruh Kualitas Layanan atas Kepuasan Siswa dan Dampaknya Terhadap Loyalitas Siswa Di SMK Kristen Salatiga. Satya Widya,, 29(2).

Reynold, Kristy E and Mark J Arnold, (2000). Customer Loyalty to the Salesperson and the Store Examining Relationship Customer in an Upscale Retail Context.Journal of Personal Selling and Sales Management, Vol. 20, no. 2, Spring, p. 89 - 98. 2000.

Ridwansyah, Iwan dan Arief Maulana. (2016).Pengaruh Bauran Pemasaran Jasa Pendidikan Tinggi Terhadap Loyalitas Mahasiswa Universitas Widyatama, http://repository.widyatama.ac.id/xm lui/handle/123456789/1293, diakses 6 September 2016, pada 23.30 WIB.

Hatane S. (2006). Ekspektasi Pelanggandan Aplikasi Bauran Pemasaran terhadap Loyalitas Toko Moderen dengan Kepuasan Pelanggan sebagai intervening (Studi Kasus pada Hypermarket Carrefour di Surabaya)", Jurnal Manajemen Pemasaran,Fakultas Ekonomi - Universitas Kristen Petra http://puslit.petra.ac.id/ puslit/journ als/dir.php?DepartmentID=MAR

Supranto,J. (2001) Pengukuran Tingkat Kepuasan Pelanggan. Jakarta: Rineka Cipta

Suprihanti, A. (2011). The Effect of Services to Customer's Loyalty (Case Study of Kentucky Fried Chicken Restaurant at Galleria Mall Yogyakarta), the $2^{\text {nd }}$ International Research Symposium in Service Management Yogyakarta, INDONESIA, $26-30$ July

Tjiptono, F. (2005) Manajemen Jasa. Edisi II.Yogyakarta: Andi Offset

Wang, I Ming dan Chich-Jen Shieh, (2006) The Relationship Between Service Quality and Customer Satisfaction: the Example of CJCU Libray, Journal of Information \& Optimization Sciences, 27 (1) 